\title{
UN CAMBIO DE PARADIGMA EN LA FORMACIÓN CONTINUADA DEL PROFESORADO: ESCENARIO, SIGNIFICADOS, PROCESOS Y ACTORES
}

\author{
Juan M. Escudero Muñoz \\ Universidad de Murcia
}

\section{RESUMEN}

La formación docente continuada es uno de los retos pendientes en todos los sistemas educativos, en el nuestro particularmente. Se han depositado en ella altas expectativas, pero no han llegado a cumplirse satisfactoriamente. Quizás, porque es un asunto más problemático y complejo que lo supuesto y no del todo comprendido, así como carente de voluntades sociopolíticas y decisiones formativas adecuadas, y coherentemente implementadas. El nuevo paradigma, reclamado hace tiempo, exige cambios profundos de los marcos teóricos en uso y estrategias consistentes que simultáneamente relacionen la profesión docente y su formación con diversos factores y dinámicas amplias y concretas. El reto actual es redefinir a fondo el horizonte a perseguir, extrayendo lecciones provechosas de los trayectos recorridos. El enfoque adoptado en este artículo plantea la necesidad de una mirada amplia y relacional sobre el escenario, los significados, los procesos y los actores involucrados. En coherencia con ello, se han de mejorar los contenidos y los procesos formativos, así como diversas corresponsabilidades y sinergias que contribuyan a crear y sostener entornos locales y sistémicos favorables a una buena formación continuada del profesorado.

PALABRAS ClAVE: formación docente, formación continua, deliberación, democracia, política educativa.

\section{A PARADIGM SHIFT IN CONTINUING TEACHER TRAINING: SETTING, MEANINGS, PROCESSES AND ACTORS}

\section{Abstract}

Continuing teacher training is one of the pending challenges in all educational systems, in our particular. High expectations have been placed on it, but they have not been satisfactorily met. Perhaps, because it is a more problematic and complex matter than was supposed and not fully understood, as well as lacking socio-political will and adequate training decisions, and coherently implemented. The new paradigm, long claimed, requires profound changes in the theoretical frameworks in use and consistent strategies that simultaneously relate the teaching profession and its training to various factors and broad and concrete dynamics. The current challenge is to redefine the horizon to be pursued in depth, drawing useful lessons from the journeys traveled. The approach adopted in this article raises the need for a broad and relational view of the setting, the meanings, the processes and the actors involved. Consistent with this, the content and training processes must be improved, as well as various co-responsibilities and synergies that contribute to creating and sustaining local and systemic environments favorable to good continuous teacher training.

KEYwORDS: teacher training, continuing education, democracy, deliberation, policy education.

DOI: https://doi.org/10.25145/j.qurricul.2020.33.06

Revista Qurriculum, 33; junio 2020, pp. 97-125; ISSN: e-2530-8386 


\section{INTRODUCCIÓN}

Existe un acuerdo prácticamente generalizado en que el profesorado y su formación continuada o desarrollo, los aprendizajes y el desempeño de la docencia son temas imprescindibles para el buen ser y funcionar del sistema educativo de cualquier país. Afectan a las personas que ejercen la profesión y a la educación del alumnado, a los centros donde laboran y a la sociedad en su conjunto. Al lado de consensos genéricos, persisten sin embargo desavenencias, controversias e interrogantes abiertos acerca de los asuntos en juego, el modo de afrontarlos y los efectos que todo ello pueda tener.

Hay discursos y poderes hegemónicos empeñados en sostener y propagar que el profesorado es el factor por excelencia de la calidad educativa (Barber y Mourshed, 2008), una tesis cuyos ecos se han extendido por doquier. No han faltado, con todo, críticas severas que la califican de simplificadora y, además, sesgada e instrumental: obedece a una agenda que al poner el foco preferentemente sobre responsabilidades particulares (abajo), trata de ocultar y eludir (arriba) otras más profundas y poderosas, estructurales y sistémicas. También hay otros discursos que confieren a las fuerzas hegemónicas macro tales y tan determinantes influencias que terminan por minimizar e incluso despreciar, por irrelevantes, los márgenes de contestación y posibilidad de la educación, los docentes y la formación (Coffield, 2012).

Este artículo pretende situarse en un territorio intermedio, aunque asumiendo la necesidad de un cambio de paradigma en la comprensión y los movimientos del escenario que nos ocupa. Las miradas y propuestas habrían de eludir concepciones y expectativas pedagógicamente ingenuas, así como aquellas que se presentan tan críticas que abocan a la impotencia y la desesperación. Es imposible desarrollar tal paradigma con la extensión y profundidad que merece. Se intentará tan solo una aproximación al mismo enunciando algunas reflexiones sobre la educación democrática y de calidad justa y equitativa, el modelo de profesorado que requiere y una formación continuada coherentes con ambos.

La profesionalidad y la profesionalización docente forman parte de un continuo con diversas etapas, todas importantes y entrelazadas: desde la atracción y el acceso de jóvenes capaces e idóneos para la enseñanza a la formación inicial, desde la selección definitiva de los aspirantes a su entrada en el sistema y sucesivo y extenso desarrollo profesional durante toda la vida laboral. La opción de poner el foco sobre esta última responde a razones de peso. Sustantivamente, porque el aprendizaje docente es una tarea siempre inacabada y de largo camino por recorrer. Está bien documentado, en efecto, que lo que se aprende al mismo tiempo que se ejerce la profesión es la fuente más decisiva para las personas que la desempeñan y los sujetos, los estudiantes muy en particular, con quienes aquellas trabajan (Eraut, 2012).

Así que se justifica contextualmente, porque, según el Ministerio de Educación y Formación Profesional (2019), más del 80\% del profesorado de la enseñanza previa a la universitaria se encuentra entre más de los treinta años y por encima de los sesenta. Dejando de lado ahora la cuestión relativa a la renovación del cuerpo docente, esos datos confieren a la formación continuada un valor muy destacable (EC, 2012). El tipo de formación y desarrollo provisto y participado (y el omitido) 
puede haber sido, en las últimas décadas, uno de los factores explicativos de la educación y los docentes con que contamos y, mirando hacia delante, una piedra de toque inexcusable del futuro por construir.

Dada la naturaleza múltiple y compleja del tema, caben diversos marcos y perspectivas para hablar del mismo, comprenderlo y gobernarlo. El marco conceptual adoptado aquí asume que es preciso atender simultáneamente a lo macro, meso y micro. De manera que, sin dejar de lado ciertos aspectos y relaciones de la formación por dentro, se tratan y valoran también otros que, por así decirlo, residen y operan por fuera. Es una manera de reconocer que los asuntos que nos ocupan revisten un carácter relacional y complejo pero inevitable.

Ello se concreta en un hilo argumental según el cual la educación por construir, el profesorado necesario y la formación continuada han de ir estrechamente de la mano. Así queda comprometida, no una perspectiva aséptica o neutral, sino otra expresamente valorativa y normativa. La transcendencia humana, cultural y social de los temas en juego así lo requiere a nuestro entender, por más que quepan otras diferentes. Y, en vez de una retahíla de generalidades, se ha querido tener en cuenta la educación y la formación docente en nuestro contexto. A fin de cuentas, porque cualquier cambio que pueda plantearse, no solo ha de estar adecuadamente fundado, sino que también ha de tomar buena nota de lo que está ocurriendo; ello es necesario para que las mejoras, estando ancladas en el pasado y el presente, comporten objetivos y decisiones realmente constructivos y transformadores.

El artículo consta de varios apartados. El primero, echando mano de un gran angular, ofrece una lectura macro. Señala que, en ese nivel, están ocurriendo ciertas pugnas entre determinadas ideologías y poderes que intentan prevalecer unos sobre otros en la definición, orientación y gobierno de la educación, sus diferentes ámbitos y agentes. El segundo esboza un cierto balance del estado de la educación (etapa obligatoria) y la formación continuada del profesorado. El tercero subraya ciertas características de una educación de calidad justa y equitativa, del modelo de profesorado que requiere y de la formación continuada necesaria. El cuarto desciende a dos dimensiones fundamentales y específicas, los contenidos y los procesos y actividades propicias a los aprendizajes docentes. El quinto, para finalizar, concluye con unas cuantas consideraciones sobre los agentes, las responsabilidades y las condiciones locales y sistémicas que es preciso disponer y aplicar.

\section{ESCENARIO, PUGNAS EN LIZA Y POLOS EN TENSIÓN}

Una mirada al escenario de fondo, que no solo circunda sino que también conforma la educación, la docencia y la formación, permite destacar determinados aspectos por fuera, dignos de ser considerados. Desde las últimas décadas del siglo pasado, la concatenación de cambios diversos y profundos en todas las esferas de la vida personal, sociocultural, tecnológica, económica y política ha ido reclamando, hasta con urgencia, alteraciones sin precedentes en la educación escolarizada, el gobierno de los sistemas educativos, los centros como instituciones y, desde luego, los docentes como profesionales. Tales cambios surgen, operan y se desplie- 
gan en niveles macro, meso y micro, activando reglas de juego, lógicas de acción e intereses cuyas relaciones están resultando, en esencia, conflictivas, problemáticas y complejas. Hacerlo explícito no debiera entenderse como algún afán innecesario de complicar las cosas sino, más bien, como un propósito de mejor entenderlas y afrontarlas.

Este tipo de análisis no son una ocurrencia, sino una de las tareas bien reconocidas por el nuevo paradigma mencionado. Hardy (2011), por ejemplo, lo ha aplicado a la formación docente y, en otra ocasión (Escudero, 2018), a la mejora justa y equitativa de la educación. En ambos casos se ha recurrido al dispositivo teórico "campo" (Bourdieu y Vacquant, 2005): es notable su potencial para acotar y definir el escenario al que aquí nos referimos.

Así, las nociones dentro y fuera antes mencionadas, como las de escenario y campo, tienen, a primera vista, no más que denotaciones espaciales. La de campo en particular, tal como lo elaboró el reconocido sociólogo francés, tiene un carácter dinámico y no solo contextual, habilitando entonces análisis y discursos más interesantes. Aplicada a la educación y la formación docente, lleva a entenderlas no como fenómenos aislados e independientes, estáticos y acabados, predeterminados o plenamente autónomos, sino como realidades abiertas y socialmente construidas a través de relaciones y tensiones difíciles, problemáticas y controvertidas, no plácidas ni consensuadas. No se trata, pues, de meros contextos vacíos, sino de espacios constituidos por elementos materiales, sociales y simbólicos que, en determinados tiempos y coordenadas, son objeto de pugnas entre ideologías (sociales, culturales, económicas, educativas) y determinados poderes e intereses que rivalizan entre sí por prevalecer y afianzarse unos sobre otros.

Pueden identificarse ilustrativamente dos pugnas en liza que provocan y legitiman dos polos extremos. El primero corresponde a una ideología cuyos discursos definen, en esencia, la educación como un bien particular, ligado preferentemente a los méritos y capacidades de los individuos. Las políticas correspondientes se concretan en formas de gobierno, gestión y distribución social de la educación basadas en criterios de utilidad y rentabilidad, competitividad, privatización de los servicios y búsqueda de la excelencia. De manera que tanto los objetivos a lograr como las estrategias y decisiones a aplicar obedecen, básicamente, a una lógica mercantil.

El segundo polo, en el otro extremo, responde a una ideología y discursos que definen la educación como un derecho esencial, como un bien común que ha de serles debidamente garantizado a todas las personas; no por estrictas razones meritocráticas, sino por una cuestión humana, social y moral de derechos. Su gobierno, gestión y redistribución, entonces, ha de poner los intereses y bienes personales y sociales comunes por delante de la rentabilidad y la meritocracia, las decisiones que beneficien a todos por delante de las que solo beneficien a unos pocos, los más ricos en todo y los más poderosos. Ello supone apostar por valores de solidaridad, participación y democracia, acometiendo coherentemente políticas, decisiones y actuaciones macro, meso y micro, comprometidas efectivamente con el derecho a la educación de calidad justa y equitativa y la adopción de otras múltiples decisiones y actuaciones múltiples, concretas y sistémicas en diversos ámbitos, entre ellos la docencia y la formación. 
Esa manera de describir el escenario-campo en cuestión no deja de ser un tanto esquemática. Desde un punto de vista teórico y práctico, entre ambos polos caben, seguramente, muchos matices y opciones intermedias; los asuntos complejos se resisten a relatos de todo o nada. Esta cautela no obsta, sin embargo, para que, vistas la educación y la formación docente bajo esta óptica, sea pertinente asumir que sobre ellas recaen y discurren pugnas como las que se acaban de apuntar. Hay realidades bien documentadas que, guste o no, muestran que determinadas ideologías e intereses hegemónicos no se limitan a pulular por las alturas. Están construyendo un escenario global enseñoreado por una economía que pone a su servicio la política y lo social: de ese modo se cercena seriamente cualquier ideario y proyectos de izquierda (Sánchez Cuenca, 2019). La secesión de las élites, que ha sido bien documentada por Arińo y Romero (2017), provoca que grandes corporaciones globales creen espacios protegidos de riqueza y un bienestar reservado a los más poderosos, una fiscalidad regresiva cuando no inexistente alojada en paraísos opacos y, con ello, una flagrante redistribución de bienes y servicios en tiempos de una abundancia sin límites. Muchas zonas del planeta y determinados sectores de la población y personas concretas dentro de los países están siendo condenadas a vivir en condiciones de indignidad, pobreza y desigualdades que debieran ser injustificables social y moralmente.

La misma educación está quedando afectada por esa ola global. Dentro de ella se crean y ocupan espacios de escolarización con pugnas desiguales entre lo público, lo concertado y lo privado. Están llegando a provocar y consentir exclusiones y segregaciones escolares y educativas (Murillo y Martínez, 2018) que cualquier sociedad y política buena no debiera tolerar; ahora, casi como ayer, las desigualdades educativas reproducen y legitiman diferencias económicas y culturales inequitativas que afectan a muchos niños y jóvenes. $\mathrm{Y}$, asimismo, sobre ese mismo escenario-campo se libran batallas discursivas y culturales pugnando entre sí por la definición y subversión de significados y valores confrontados: igualdad-libertad, educación-sociedad-individuos, contenidos y formas del currículo, la enseñanza-aprendizaje y la evaluación, aspiraciones e identidades estudiantiles, docentes y ciudadanas, prisioneras de la cultura selfis autoexpresiva, filosofías del yo primero y sujetos ensimismados, reduciendo lo público y lo común a bienes, preferencias y consumo de particulares (Giroux, 2016).

En lo que respecta al gobierno, la gestión y los agentes involucrados, se han dispuesto y aplicado mecanismos de vigilancia, regulación y control. No solo van destinados a implantar y requerir prácticas eficientes y productivas (performatividad), y evaluaciones marcadas por el imperativo de elevar sin resuello los niveles de rendimiento. Incluso se dirigen a ocupar y colonizar el alma del profesorado, los directivos y administradores, el mismo alumnado y las familias (Ball, 2015). De manera que por más que puedan existir matices intermedios entre los dos polos seńalados, y que seguramente la dominación macro no sea totalizadora, las tensiones y pugnas dentro del campo no ocurren sobrevolando algún planeta lejano. De unos u otros modos conforman y penentran en el mundo de las ideas, decisiones, prácticas y subjetividades en este concreto que habitamos, muy particularmente en la educación, sus diferentes actores, los y las docentes, su profesionalidad y profesionalización. 
No está de más convocar alguna otra óptica de cara a componer una visión todavía algo más ajustada acerca de cómo operan las pugnas y tensiones en liza. Echando mano de la teoría de la complejidad y el realismo crítico (Cochram-Smith, Ell, Grudlow, Highe y Mill, 2014) han realizado advertencias pertinentes a la educación y formación del profesorado. Sostienen que, dada la pluralidad de elementos, agentes, relaciones y poderes situados y en contexto, nuestros campos no se rigen por una lógica de relaciones causas-efectos lineales, previsibles, jerárquicas y ciertas, sino por otra bien diferente. Como las pugnas en cuestión se asientan sobre arenas movedizas, los asuntos sobre los que versan son personal, social y culturalmente construidos, recíprocamente interactivos, imprevisibles, tocados de incertidumbres. Esta perspectiva puede sernos útil para entender mejor por qué y cómo ciertos proyectos supuestamente alineados, estén alineados con uno u otro de los polos mencionados, no discurren mecánicamente ni sin contestación. En tiempos de mercantilización generalizada, no todo lo que ocurre está regido por dicha lógica ni todos los agentes concernidos condenados a realizar pasivamente sus objetivos. Igualmente, existen discursos y proyectos alineados con el bien común de la educación, pero no por ello, y lamentablemente, podría desconocerse que sus mejores intenciones y propuestas siguen todavía en el tintero.

Tampoco convendría pasar por alto, sin embargo, que así como la realidad es social y humana construida más allá de relaciones prefijadas y obedeciendo a alguna linealidad causas-efectos, tampoco es completamente libre, dado el peso «objetivo» de determinados factores estructurales y sistémicos que la constriñen. Las causas más profundas de la indignidad humana y las desigualdades que padecen muchas personas hacen imposible para ellas unos mínimos de calidad de vida e, igualmente, los citados patrones de segregación escolar hacen que las personas, confinadas en guetos, no puedan acceder y participar de la calidad educativa justa y equitativa, el profesorado necesario y la formación continuada requerida. De ahí, entonces, la necesidad de un nuevo paradigma que nos ayuda a desvelar aspectos de dentro y de fuera, las pugnas que se están librando en el campo y las lecciones por aprender.

\section{UN PAR DE APROXIMACIONES AL ESTADO DE LA EDUCACIÓN Y FORMACIÓN CONTINUADA DEL PROFESORADO}

Dada la extensión razonable de este texto, ha lugar a balances detallados y representativos. Para nuestro propósito, basten algunos indicios parciales, aunque no por ello irrelevantes.

a) Respecto al estado corriente de la educación (la obligatoria más en concreto), no cabe duda de que, tras la transición democrática, se han realizado caminos y cubierto etapas comparativamente mucho mejores que las heredadas de la dictadura. Se ha logrado una educación más democrática y más extendida en años y, en ciertos aspectos, más justa y equitativa incluso. Ha habido, con todo, vaivenes y turbulencias gestadas y desarrolladas al filo de nuestras propias pugnas por dentro 
y por fuera, así en niveles macro y meso como micro, estos más cercanos, afectando a la educación en los centros, al profesorado y a la formación docente.

Veamos tan solo un par de referencias con la idea de destacar algunas «asignaturas» pendientes en nuestra educación. La primera tiene que ver con ciertos datos que, una y otra vez en las últimas décadas, revelan, al lado de ciertos logros, desigualdades e inequidades educativas manifiestas (Martínez García, 2017). Descendamos a uno más concreto y significativo: tras revisar diversas fuentes e informes recientes (Escudero, 2018), se ha observado que, sumadas las tasas medias de no graduación ESO y las del abandono educativo temprano -AET- (en jóvenes entre los dieciocho y veinte años), arrojan un porcentaje algo superior al $40 \%$. Ello ha sucedido al mismo tiempo que, en el último lustro, se han documentado progresos en las tasas de graduación ESO, así como en AET. El panorama estaría mostrando no tanto que no haya habido ciertas mejoras escolares, sino que no todo el alumnado se ha beneficiado equitativamente de las mismas. Al llevar a cabo análisis atendiendo a determinadas características del alumnado, múltiples indicios hablan de que el que pertenece a las familias y entornos más desfavorecidos en lo social y cultural casi no ha participado de aquellas: los logros alcanzados han resultado inequitativamente distribuidos y participados.

Dicha referencia adquiere una mayor significación todavía si se compara con esta otra. Para las tasas de la población (entre veinticinco y treinta y cinco años) que ha cursado y logrado alguna titulación universitaria, el porcentaje resultante viene a coincidir con el anterior, también aproximadamente el 40\%. Resulta difícil negar que, así las cosas, nuestro sistema educativo adolece de una enorme brecha de inequidad, un reto conocido y traducido a declaraciones a favor de corregirlo, pero palpablemente alterado. De hecho, hoy por hoy bastantes discursos y palabras altisonantes en pro de la libertad de elección educativa por las familias (aliada con la libertad de elección del alumnado por algunos centros) son más reveladores de lo que cabría suponer. No están dando señas fehacientes de que la justicia y la equidad educativa son horizontes muy difíciles y complejos de alcanzar, sino que en realidad están bajo la seria amenaza de ser valorados como obsoletos y prescindibles. Y lo que es más grave, ello no pacere ser un dictamen reservado a las élites, sino bien atractivo para amplios sectores de las clases medias, amparado por ciertos poderes públicos y no suficientemente contestado por otros.

La segunda asignatura pendiente tiene que ver con otras evidencias relativas a la enseñanza, los aprendizajes y su evaluación ligada al día a día de centros, docenes y estudiantes. Son escasos nuestros conocimientos contrastados sobre lo que realmente sucede dentro de centros y aulas, acerca de la calidad o la pobreza de la vida docente y estudiantil dentro de ellas o el grado en que los aprendizajes más importantes, que no son siempre los evaluados, se están logrando o siendo dejados de lado. En el caso de disponer de fundados y valiosas informaciones al respecto, podría formularse quizás con mayor precisión otro desafío aún más de fondo y retador. Posiblemente, lo que está en jaque es el modelo de escolarización heredado del pasado, no alterado sustancialmente y por tanto dominante, por más que cada día surjan nuevas razones para cambiarlo a fondo. Está en entredicho el valor intelectual, emocional y social de los conocimientos y la cultura seleccionada y provista por los 
centros y aulas, a la orden del día el desbordamiento de las instituciones, del profesorado y otros actores, las dificultades de, en estos tiempos y con la niñez y juventud de ahora, lograr las complicidades docentes y estudiantiles (Labaree, 2011) sin las cuales la enseñanza-aprendizaje resulta algo tan titánico para la mayoría como, en oasis particulares, reservada para los «mejores». No parece fuera de lugar el reto y pronóstico inquietante formulado al respecto por Novoa (2019): o se acometen ciertos cambios con urgencia o la educación y la escuela pública conocidas serán confinadas, más y más, a los márgenes, reemplazadas por una creciente privatización y dejadas en manos de la digitalización tecnológica, lo que ahondará, todavía más, la brecha de las desigualdades.

b) Nuestro actual sistema de formación continuada del profesorado, que surgió con fuerza en los ochenta (creación de los centros de profesores o servicios equivalentes con otras denominaciones) y se ha mantenido con muchas turbulencias hasta la fecha (solo en algunas CC. AA., pues en otras ha sido cercenado o sencillamente eliminado), ofrece un panorama peculiar al día de hoy. Está claramente afectado de una fuerte fragmentación, una vez que las competencias en la materia fueron descentralizadas. Hay constancia, sobre todo cuantitativa, de que, en efecto, en las últimas décadas han sido muy considerables los recursos financieros, el personal formador dedicado y los programas y actividades formativas en las que ha participado el profesorado. Y, en estos momentos, dilatados los lugares, tiempos y oportunidades de información y ¿̨formación?, particularmente cuando la modalidad online ha hecho acto de presencia, podría ser raro el profesorado que ha quedado completamente al margen. Está fuera del alcance de este artículo la intención de ofrecer una mirada ni siquiera aproximada a sus aspectos por dentro y fuera. De manera que el ligero balance que se ofrece a continuación es obligadamente cauteloso. Entre otras razones porque, en este como en otros ámbitos educativos, somos deudores de un modelo nacional de hacer reformas que suele dedicar mayores esfuerzos a legislar e implantar cambios e innovaciones que, como sería conveniente, a seguir y evaluar cuál es su devenir en diversos contextos, prácticas y resultados.

Por extraño que parezca, en realidad no ha habido informes que hayan documentado alguna evaluación a escala nacional o autonómica, haciendo balances fundados sobre cuál y en qué haya realmente consistido la formación, las condiciones y los procesos de implementación de tantos proyectos. Todavía menos, acerca de si las experiencias y la participación de diferentes agentes (docentes, formadores, equipos directivos, inspectores de la administración, etc.) han propiciado o no aprendizajes docentes conectados con la renovación pedagógica, el mejor funcionamiento de los centros, las experiencias escolares y los aprendizajes del alumnado.

Es sintomático de lo que se dice el hecho de que, mal que nos pese, la fuente a la que se recurre para referirse a datos empíricos que ofrecen alguna descripción del panorama de la formación corresponde a sucesivos estudios de la OCDE (TALIS, 2014, uno de ellos), referidos al profesorado de la ESO. Ha habido alguna investigación de alcance sobre políticas y prácticas de innovación educativa (Marcelo, 2011), así como alguna otra más reciente y específica (no representativa) sobre la formación continuada. Se llevó a cabo, entre 2012 y 2016, por varios investigadores e 
investigadoras de diferentes universidades y CC. AA., Andalucía, Canarias, Galicia, Murcia y País Vasco (ver Monográfico Formación Continuada, 2017). Los indicios que se presentan a continuación no responden punto por punto a todas las conclusiones de las fuentes citadas y merecen ser tomados, pues, solo a título ilustrativo.

Uno de tales indicios apunta a que, en la última década, la mayoría del profesorado de la educación obligatoria, entre un $75 \%$ y algo más del $80 \%$ según los años, ha participado en diversas actividades, experiencias y programas formales de desarrollo profesional, además de un abanico elástico e incuantificable de otras y otros episódicos, informales, quizás elásticos. Ello podría aducirse como una muestra de que muchos y muchas docentes valoran y reconocen que la formación y la innovación les son necesarias y convenientes, así como que en ellas se implican y han persistido porque les reportan algún provecho, así como también al alumnado con el que trabajan. Ello habría sido así, a pesar de que dicha formación sigue siendo vista, por lo general, como una cuestión personal, voluntaria y ocasional. No algo inscrito en el núcleo de la cultura profesional, institucional y de las administraciones como un derecho y un deber, ni pensado y vivido como algo consustancial al modo de ser, aprender y ejercer el oficio ni, tampoco, perteneciente a las tareas, responsabilidades y condiciones que efectivamente han de ser propiciadas por otros actores como los equipos directivos, los inspectores o, más allá de obvias apelaciones, las administraciones educativas.

El hecho de que la modalidad formativa más citada por el profesorado, cuando se le pregunta por ello, sea la realización de cursos con expertos sobre temas de enseñanza-aprendizaje de las materias curriculares y, más recientemente, la formación online, podría hacer suponer que el desarrollo profesional se piensa y se practica como algo yuxtapuesto, colateral, ocasional y externo al día a día de la profesión. En ese mismo sentido, como un asunto de uso y consumo particular y no tanto social y colegiado. Igualmente, da pie a pensar que la formación en cuestión consiste, sobre todo, en el acceso y el trabajo sobre metodologías y recursos presuntamente innovadoras para ponerse al día, prevaleciendo la búsqueda de respuestas prácticas a cómo hacer la docencia sobre otras, dignas de aprecio, como la indagación acerca de los porqués y paraqués, calificados habitualmente como teóricos, poco útiles e innecesarios.

Solo en algunos estudios de caso (ver, por ejemplo, el citado Monográfico para más detalles) se han podido observar experiencias y actividades de formación en centros con proyectos bien articulados de innovación pedagógica y formación docente, actividades en grupo centradas en la elaboración y desarrollo conjunto de materiales, trabajo situado en los lugares de trabajo sobre metodologías como el aprendizaje por proyectos, el aprendizaje en servicio, innovaciones pedagógicas integrando TIC y creación de comunidades de aprendizaje presenciales o virtuales. El panorama general, sin embargo, no ofrece muestras de actividades formativas articuladas en torno a la investigación-acción, la reflexión sobre la enseñanza-aprendizaje con propósitos de reconocer y comprender las prácticas y acometer, de ese modo, dinámicas de mejora. A pesar de los buenos avales teóricos con que cuenta una formación consistente en potenciar la observación entre iguales, la ausencia de un diseño de unidades didácticas compartidas y acompañadas de un seguimiento 
reflexivo del desarrollo de las mismas en las aulas o, asimismo, de la realización de visitas a otros centros donde se están llevando a cabo experiencias interesantes, exceptuadas honrosas excepciones particulares, parece ser generalizada.

Haciendo bueno lo que ahora se sostiene al reclamar que la formación docente no puede acotarse a lugares, tiempos, relaciones y oportunidades específicas, no cabe duda de que el profesorado va aprendiendo de muchas formas y con múltiples relaciones: el negarlo sería, sencillamente, desconocer buena parte de lo que está aconteciendo. Ello no obsta, sin embargo, para dejar constancia de que el panorama de la formación está poblado de actividades múltiples, tal vez no siempre bien fundadas e integradas. Muchas de ellas pueden estar siendo fragmentarias, episódicas, fugaces, cambiantes, insostenibles; provocadas por modas que van y vienen, más propias de un modelo de aprendizaje docente pragmático, tendente a valorar y promover nuevos modos de hacer presuntamente innovadores y prácticos, no por ello bien fundados y provechosos. Así las cosas, otros modos de pensar, vivir y promover un aprendizaje docente, llevado a cabo como una construcción personal, colegiada, teórica y práctica, reflexiva y transformadora, siguen pendientes de habitar entre nosotros, de consolidarse y de ocurrir sistémicamente, no solo en casos aislados (Trillo, Nieto, Martínez y Escudero, 2017).

Exceptuados casos singulares encomiables, que ciertamente existen, esos indicios pueden ser bastante representativos de lo que se está diciendo. Se refuerzan y complementan, además, al poner el foco sobre los contenidos, una dimensión relevante del desarrollo profesional. Los resultados procedentes de cuestionarios respondidos por muestras significativas de docentes revelan, en efecto, que los temas más tratados se refieren, como se ha apuntado antes, a metodologías didácticas y TIC, algo menos a los objetivos del aprendizaje escolar (ahora afectados por la ola de las competencias, estándares y rúbricas, que son de obligado cumplimiento administrativo). Algo similar estaría sucediendo con la tarea difícil de comprender y atender a la diversidad del alumnado: ello es señalado por un buen número de docentes sosteniendo que es uno de los vacíos de la formación continuada, así como también con otras cuestiones relativas a aspectos organizativos de los centros, su funcionamiento y participación en las tareas que por principio también corresponden al profesorado.

También se tratan, aunque menos de lo esperable, cuestiones relativas al desarrollo evolutivo y el aprendizaje del alumnado (sobre todo en claves psicológicas), así como las que tienen que ver con la elaboración y desarrollo de proyectos de innovación en ciclos y departamentos. Los contenidos menos tratados, y hasta omitidos, son los relacionados con las bases epistemológicas, sociales y culturales del currículo, la enseñanza-aprendizaje, la diversidad del alumnado y la importancia de los contextos sociofamiliares del alumnado. Otros, referidos a las vivencias y emociones de una profesión desbordada por diversos frentes (condiciones del puesto de trabajo, clima, relaciones y cultura organizativa de centros, ciclos y departamentos, coordinación y colaboración con los colegas), no tienen la presencia que, por principio, cabría esperar que tuvieran en los programas oficiales de formación. Dicha formación parece más preocupada por las facetas racionales de la docencia que por las emocionales y sociales. Más por los imperativos de una lógica restrictiva de la prác- 
tica que por cultivar y promover las "herramientas» cognitivas, emocionales, sociales, éticas necesarias para la profesión. Como cabe inferir de lo dicho, no es común tomar nota y abordar aquellos asuntos a los que se viene haciendo referencia en el texto, relativos a los aspectos de dentro y de fuera de la formación.

En resumidas cuentas, los indicios señalados infunden sospechas de que, en aras de tornar práctica la formación continuada, bien percibida y valorada por amplios sectores del profesorado, podría estar corriendo serios riesgos de perder rigor intelectual, una verdadera relevancia y significatividad emocional y práctica, desaprovechando oportunidades de fertilizar más adecuadamente las vidas, tareas y responsabilidades docentes. Privado el desarrollo profesional de miradas y desafíos más allá del sentido común utilitarista, descuidando temas, interrogantes y sólidos referentes conceptuales, carecería de consistencia formativa y, asimismo, permanecería ajeno a las grandes cuestiones relacionadas con la justicia, igualdad, mejora de la condición humana y la vida común en democracia. En realidad, no es que algunos asuntos realmente desafiantes hoy (racismo, xenofobia, violencia de género, acoso entre iguales dentro y más allá de los centros, medio ambiente, interculturalidad, etc.) estén ausentes de las inquietudes y ocupaciones docentes. Pero, tal como está siendo pensado y llevado a cabo el desarrollo profesional, esos desafíos y otros similares no suelen ir más allá de planteamientos y respuestas aisladas. Con frecuencia, son relegados hacia otros agentes no docentes en sentido estricto: orientadores, profesionales técnicos de servicio a la comunidad u ONG. En todo caso, conviene retener la idea de que el hecho de que tales indicios correspondan al panorama en general no significa, como se ha dicho, la ausencia de oasis de formación e innovación encomiables; sin embargo, por ello mismo parece ser más propiedades de particulares (algunos docentes, grupos, colectivos y centros), pero no del sistema en su conjunto.

No habría que tratar de establecer, sin más, la existencia de relaciones lineales entre las citadas pugnas ideológicas y poderes hegemónicos descritos (aspectos de fuera) y el estado de la formación continuada que se acaba de ofrecer ilustrativamente (aspectos por dentro): es preciso atender a la teoría de la complejidad también mencionada. Sería de ingenuos suponer, sin embargo, que la educación provista como la formación docente prevalente son atribuibles, en exclusiva, a las concepciones, acciones u omisiones personales, pedagógicas y organizativas de los actores más directamente involucrados. Cabe sostener, cuando menos, que alguna parte importante de lo que nos está ocurriendo no es ajena a dejaciones, intencionadas o presas de la inercia, sobre las cuales, paradójicamente, convergen poderes e intereses macro y meso que social y educativamente son diversos; y, a su modo, poderes, intereses y agentes que se mueven y deciden en los ámbitos micro, centros, profesorado y otros agentes involucrados. 


\section{EDUCACIÓN DE CALIDAD JUSTA Y EQUITATIVA, MODELO DE PROFESORADO Y DESARROLLO PROFESIONAL}

\section{A) UNA EDUCACIÓN DE CALIDAd JUSTA, EQUITATIVA Y GENUINAMENTE INCLUSIVA}

Los presupuestos e implicaciones de una educación como bien común y derecho esencial que asiste a todas las personas (polo dos descrito) ha sido bien argumentada y postulada por discursos curriculares y pedagógicos bien reconocidos y divulgados desde múltiples perspectivas (Ainscow, Dyson y Weiner, 2014; Escudero, 2018; Guarro, 2002; Young, 2013). Puede destacarse sucintamente una serie de valores, criterios y principios como los que se citan seguidamente.

- Un currículo que sea culturalmente diverso (inclusivo de alfabetizaciones múltiples), intelectualmente riguroso y potencialmente formativo de todo el alumnado, vertebrado en torno al poder de las disciplinas y diferentes formas de organización de los contenidos, reconocedor de los estudiantes, sus características personales, sociales y culturales y, al tiempo, comprometido en expandir las capacidades y disposiciones que las personas necesitan para leer, comprender, interpretar y transformar el mundo que habitan.

- Una enseñanza cuyos entornos, oportunidades, metodologías, recursos didácticos relaciones y evaluación promuevan la construcción activa, personal y social de los estudiantes de la cultura escolar, cultivando y promoviendo comprensión profunda, desarrollo de capacidades cognitivas superiores, actitudes y valores cívicos y éticos. Y no tanto ni solo aquellas competencias estrechamente ligadas a la formación de una ciudadanía productiva, sino capacidades (en el sentido de A. Sen) necesarias para el bienestar humano y la calidad de la vida personal y social, tal como acertadamente ha planteado Howard (2018) contrarrestando una lógica del interés material y económico con aquella otra que gira en torno a una buena vida humana, con los demás y con el mundo.

- Una educación y enseñanza que reconoce, valora y responde a las diferencias y diversidades múltiples del alumnado, velando expresamente por que no se traduzcan en diferencias en el acceso y participación en los derechos formativos a todos y todas debidos. Planteada con miradas amplias, asume que las metodologías y los aprendizajes que se acaban de citar son relevantes, pero, al mismo tiempo, también lo son aquellos principios derivados de una epistemología equitativa (Gale, Mills y Cross, 2017) que tome en consideración y amplíe los contextos de vida y la cultura sociofamiliar del alumnado y el establecimiento con ellos de vínculos, complicidades y relaciones simultáneamente de apoyo, responsabilidad y esfuerzo.

- Muy singularmente, todo lo anterior apela e incluye valores y atenciones basados en el cuidado, en la creación y el sostenimiento de un clima educativo con relaciones de cooperación y apoyo mutuo entre los estudiantes y de ellos con el profesorado, prestando suma atención a las facetas sociales y emocionales del aprendizaje, al desarrollo de imágenes positivas de sí mismos, al cultivo y desarrollo del sentido de pertenencia e identificación favorable con la escuela, 
el cuidado especialmente centrado en crear y sostener relaciones de apoyo, afecto y responsabilidad, emociones y vínculos con el alumnado que desarrollen su visibilidad, sentido de pertenencia e identificación con la escuela, los docentes y los propios aprendizajes. A fin de cuentas, porque de cara a desarrollar aprendizajes cognitivos, emocionales y sociales, las relaciones de cuidado y genuinamente humanas entre los actores son esenciales a la calidad de la vida escolar, tan necesaria y debida al alumnado como al profesorado. - Para hacer efectivo y sin discriminaciones de ningún género el derecho al bien común de la educación, es preciso adoptar y movilizar ideas, capacidades, políticas y prácticas que lo redistribuyan justa, equitativa e inclusivamente. No solo, por tanto, en oasis educativos de calidad y excelencia, sino a lo largo y ancho de todas las aulas, escuelas y, todavía más, el sistema en su conjunto.

\section{B) El profesorado NeCESARio}

Sin restarles la importancia que tienen los aspectos por fuera, no hay excusas a la tarea de responder a un tema específico cuyas raíces por dentro son innegables: qué profesorado se necesita para perseguir y apostar en firme por la calidad educativa propuesta. Viene de lejos la convicción de que la profesión docente es eminentemente humana, social, cultural. Tiene en sus manos (al lado de otros agentes, desde luego) la enorme y apasionante tarea de lograr, con las personas más jóvenes con las que labora, aquellas complicidades que hacen posible conservar y recrear el bagaje cultural del pasado y el presente, desarrollar y aprender las «herramientas» múltiples e integradas que les permitan vivir razonablemente bien sus presentes y hacer otro tanto con dignidad, después, en las diversas esferas de la vida.

Es comprensible, entonces, que una y otra vez se haya insistido en que la profesión docente reviste múltiples elementos constitutivos (ideas, creencias, vivencias e identidades, capacidades, actitudes, modos de hacer y compromisos, valores y propósitos). Al considerar la naturaleza de cada uno de ellos y sus relaciones con el conjunto, se han definido modelos diferentes de profesionalidad -técnica, académica, interpretativa, crítica, restringida, ampliada- (Hargreaves y Goodson, 1996; Menter, Hulme, Elliot y Lewin, 2011; para una buena síntesis, EC, 2013).

Para relacionar la educación justa e inclusiva subscrita y la profesionalidad docente coherente con ella, puede servirnos una mirada a diferentes éticas profesionales: centrada en la justicia y la crítica, referida a la propia formación y el cuidado, comunitaria-democrática (Escudero, 2016). Una ética de la justicia apela a una profesionalidad articulada sobre el reconocimiento del derecho esencial a la buena educación que asiste a todas las personas; por coherencia, requiere y aboga por docentes justos y equitativos, firmemente convencidos de que sus contribuciones, por modestas que pudieran ser, son imprescindibles para tratar a los estudiantes como sujetos de derechos, dejar huellas humanas y sociales positivas en sus vidas, sosteniéndolo así en sus creencias y concepciones como en las relaciones y las prácticas. No en abstracto, sino proyectadas y realizadas a través de un currículo, enseñanza-aprendizaje y evaluación democrática y equitativa. No asépticas sino firmemente comprometi- 
das con una educación inclusiva en sus diversas facetas y combatiendo la exclusión en aquello que le concierne. Este presupuesto ético en pro de una profesión justa y equitativa entiende que ello no debiera ser pensado como algo propio de docentes militantes, extraordinarios y radicales, sino como algo común a todo el profesorado, si realmente se toma en consideración el imperativo de garantizar a todos el bien común y esencial de la educación.

Desde la idea de una profesión acorde con una ética de la crítica, se asume que la faceta que se acaba de señalar es necesaria, pero no suficiente. De manera que tiene razón de ser una profesionalidad bien informada y crítica de los factores y dinámicas poderosas que, en niveles macro y meso, obstaculizan y vulneran el derecho a la educación: no cabe, pues, la ingenuidad pedagógica. También reconoce que otros factores, agentes y decisiones diferentes, pero que también dificultan la justicia y equidad educativa, pueden anidar y operar sutil o explícitamente en niveles meso y micro (organizativos, pedagógicos, profesionales); de ahí la necesidad de disposiciones autocríticas, la resistencia a tirar la toalla y el empeño por crear y fortalecer márgenes de posibilidad, propios y con otros, caminos esperanzados para no desperdiciar el potencial transformador que la educación tiene en sus manos.

Precisamente por esa dirección, la ética de la profesionalización, que sitúa el desarrollo profesional en claves deontológicas, le confiere una razón de ser más allá de los estrictos gustos o preferencias personales, pues lo define como algo necesario para mejor responder a derechos y necesidades del alumnado. Dicho con otras palabras, educarse y aprender al mismo tiempo que los docentes tratan de educar y ayudar al alumnado a que aprenda no sería una opción libre sino una cuestión de deontología profesional. La verdadera formación del profesorado no se acaba en sí y para sí, sino que los conocimientos y capacidades, además del valor que como tales han de tener, están llamados a ser transitivos, a facilitar mejor la trayectoria escolar y los aprendizajes del alumnado con el cual se trabaja. De ahí, la importancia de una buena formación y desarrollo profesional, no como una opción particular y voluntaria sino como una cuestión de deontología.

Por su parte, la ética del cuidado, que entronca con la cara más humana de la profesión, resalta y confiere valor a lo emocional y social, así en lo que toca a quienes la ejercen cuanto, también transitivamente, afecta al alumnado u otros agentes con los cuales aquella se ejerce. No solo, por tanto, importa lo racional, sino también aspectos tan relevantes como son el equilibrio personal y la madurez emocional, la generosidad, el altruismo y el sentido más humano de la docencia, todas ellas características esenciales del cuidado de otros. Tiene que ver, asimismo, con el cultivo y el apoyo conveniente para que cada docente y el colectivo profesional del que forma parte desarrollen sentido de identidad, pertenencia, compromiso e implicación con la educación y los centros donde labora, características tan beneficiosas para el cuidado del alumnado como el cuidado de sí mismos y los colegas.

Finalmente, la ética comunitaria democrática pone el foco en que lo que los docentes son, saben, viven, aprenden y desempeñan radica en conocimientos y experiencias personales y socialmente creadas y redistribuidas, en voces y saberes múltiples a tomar en consideración, en línea, por ejemplo, con planteamientos dignos de atención hechos por Aguiló Bonet (2009) al referirse a valores y princi- 
pios de una justicia cognitiva y una epistemología democrática. Ambas contribuyen a que los proyectos, las decisiones y las prácticas escolares y profesionales sean genuinamente participativas y democráticas, incluyan voces diferentes y concierten roles complementarios: son imprescindibles para crear la malla de corresponsabilidades y sinergias requeridas por proyectos curriculares, pedagógicos y organizativos, de profesorado y formación que apuesten por la calidad educativa de la que se viene hablando.

Es manifiesto que al definir la profesión a la luz de esas perspectivas éticas se está elevando la mirada y situando la docencia en una compleja y exigente simbiosis de facetas cognitivas, emocionales, sociales y éticas. No se plantea como una cuestión de moral categórica de los sujetos, contextos y dinámicas macro y meso ni, tampoco, como un marco que exclusivamente interpela al profesorado. En consonancia con lo que se viene argumentando, lo que procede es tomarlo, más bien, como un marco de referencia sobre el cual deliberar y reflexivamente conectar los tres elementos del eje central: una buena educación, el profesorado necesario, un consecuente desarrollo profesional.

\section{C) Desarrollo y aprendizaje profesional coherentes}

Como una determinada idea de la educación remite a una complementaria de la profesión docente, esta, a su vez, requiere un coherente desarrollo profesional, en las ideas, políticas y práctica, una tesis suscrita las últimas décadas continuadas (Darling-Hammond, Hyler y Gardner, 2017; Marcelo y Vaillant, 2009; Monográfico Formación Continuada, 2017; Stoll, Harris y Handscomb, 2012; Timperley, 2010).

La investigación y las teorías disponibles, así como una variedad ingente de proyectos, actividades y experiencias llevadas a cabo en este ámbito, también revelan tensiones y fuerzas entre factores por dentro y por fuera. Conforman un panorama muy dispar entre países, territorios y dentro de cada uno de ellos. Los reconocimientos, las apelaciones y promesas depositadas en la formación continuada van acompañadas, al mismo tiempo, de discrepancias, actuaciones idóneas, inadecuadas u omisiones, no pocas contradicciones entre lo que se dice y se hace, además de continuas lamentaciones.

Hablando en general, el cambio de paradigma ha sido reclamado más en las teorías y declaraciones que coherentemente traducido a políticas, decisiones y prácticas. En aquellas, se han ido dejando atrás palabras y significados declarados obsoletos (formación como entrenamiento, reciclaje, actualización docente), actualmente resignificados y remplazados por otros más pertinentes y prometedores (formación continuada, desarrollo profesional, aprendizajes docentes, formación-innovación). Pero en las políticas, decisiones y actuaciones, persisten regularidades inveteradas y sostenidas, como se ha hecho constar antes, a pesar de otros avisos para navegantes.

Sobre los supuestos e implicaciones respecto al desarrollo profesional que se seńalan seguidamente sobrevuela, de nuevo, la advertencia de que la mirada específica por dentro no es ajena a la que ha de dirigirse hacia fuera, pues guardan entre sí algún tipo de relaciones. En lo que respecta a ciertos supuestos, son con- 
sistentes las apelaciones a un cambio de paradigma: a las fuentes que se acaba de citar es pertinente añadir otras ocupadas en tocar más específicamente la cuestión (Borko, Jacobs y Koellner, 2010; Easton, 2008). Coinciden en entender la formación como desarrollo profesional y este, a su vez, como aprendizajes docentes que contribuyan a la renovación pedagógica y los aprendizajes esenciales del alumnado. De manera que no basta cualquier proyecto y experiencia de formación, sino aquel que realmente lo sea, contribuyendo a facilitar aprendizajes docentes consecuentes. Se ha ampliado la mirada poniendo el acento en que aquellos son múltiples y construidos activa, personal y colegiadamente por los sujetos, importando tanto lo que se aprende cuanto cómo se aprende, para qué y cómo se usan en la vida cotidiana, y son sostenibles (Kelly, 2006). Y procede advertir que tan relevante es lo que vale la pena aprender como lo que conviene desaprender. De tales supuestos forma parte el reconocimiento generalizado de que, sin merma de otras etapas de la profesionalización docente, la situada y correspondiente a los contextos, relaciones y prácticas de la profesión, como también les sucede a otras muchas profesiones, es decisiva en la adquisición, el ajuste, desarrollo y consolidación de los repertorios conceptuales, vivenciales y prácticos del trabajo (Eraut, 2012); aunque desde luego y según la calidad de aquella, la experiencia, sin más, no es necesariamente una buena consejera.

De considerar mínimamente fundados y razonables tales supuestos, determinadas implicaciones, derivadas de los mismos, habrían de ser tomadas en consideración, seria y coherentemente. Sin descartar que los y las docentes se forman (sensu lato) tanto en actividades formales como informales y, asimismo, en tiempos, lugares, experiencias y relaciones múltiples, un desarrollo profesional coherente con lo que se viene diciendo habría de ser intencionalmente planificado (como la educación escolarizada). Reconocido, inscrito, valorado y comprometido en y por el núcleo constitutivo de la cultura docente y la cultura de los centros (no yuxtapuesto, ocasional, marginal). Habría de ser visto y planteado simultáneamente como un cometido personal y social; como un proceso abierto al conocimiento profesional de base (teorías, métodos, materiales didácticos disponibles que vale la pena conocer y reflexivamente utilizar) y como un filtro mediador entre el mismo, los propios contextos, estudiantes y prácticas. Ha de acontecer y desarrollarse estrechamente ligado a la vida y los temas de la práctica (docentes y estudiantes u otros) y resultar significativo para el profesorado, tomando en consideración la sabiduría de la práctica, reflexionando sobre ella para comprenderla y mejorarla en lo que fuere menester.

También el desarrollo profesional está llamado a ser entendido bajo los auspicios de derechos docentes que han de garantizarse (condiciones laborales adecuadas del puesto de trabajo, estructuras de tiempo y redistribución idónea de tareas y responsabilidades, disponibilidad de recursos necesarios, apoyos y relaciones intelectuales, emocionales y psicosociales en los lugares de trabajo). Y, simultáneamente, como algo sustancial de deberes docentes (implicación en desarrollar y expandir aprendizajes necesarios, conectar formación e innovación, participación responsable en proyectos institucionales y colegiados, trabajo y trato cuidadoso y recíproco del alumnado y los colegas, compromisos con una buena educación). 
En resumidas cuentas, los mensajes al respecto parecen relativamente claros y consistentes: o se afrontan coherentemente y con determinación el sentido y las finalidades del desarrollo y aprendizaje profesional docente, incluyéndolo en el núcleo del ser, saber y hacer de la profesión, o, posiblemente, la formación continuada seguirá siendo marginal e irrelevante. O se plantea y compromete como un derecho y un deber, como una tarea personal, social e institucional, o seguirá dependiendo de opciones y decisiones particulares, ocasionales y voluntarias, capaces de minar proyectos conjuntos. Caben todos los matices que se quieran respecto a tales apelaciones. Pero por más vueltas que se le den al tema, y sabido lo que sabemos, el tan reclamado cambio de paradigma seguirá eruditamente tratado en la literatura, pero inoperante en la práctica. No estaría de más, concretamente en nuestro contexto, poner sobre la mesa estas y otras cuestiones, deliberar y concertar sobre las mismas y, sin más rodeos, trazar los nuevos caminos que merezcan ser transitados.

\section{LOS CONTENIDOS Y LOS PROCESOS DE FORMACIÓN Y APRENDIZAJE DOCENTE}

Estas dos dimensiones del desarrollo profesional tienen su propia entidad y, a efectos expositivos, se tratan sucesivamente, aunque, en los proyectos y la acción, han de ser convenientemente integradas. Básicamente, porque los contenidos, por relevantes y valiosos que pudieran ser, a menos que sean activamente transformados con ciertos procesos en aprendizajes, serán estériles e inertes; asimismo, por necesarias que sean ciertas actividades y procesos, a menos que versen sobre contenidos sustantivos y relevantes, resultarán meras formalidades inexpresivas y hueras. Biesta (2015) lo ha planteado con claridad: no importan solo las referidas a cómo se aprende (estudiantes, docentes u otros), sino lo que vale la pena aprender, algo propio de la educación como empeño teórico, fundado y moral que ha de ser bien justificado y fundamentado. De manera que, aunque las bases psicológicas son necesarias, no bastan, sino que han de integrarse con fundamentos epistemológicos, socioculturales, antropológicos, políticos y éticos.

\subsection{LOS CONTENIDOS COMO SUSTANCIA DE LA FORMACIÓN DOCENTE}

Uno de los temas controvertidos en este ámbito es el relativo a la sustancia y las formas del desarrollo profesional. Los planteamientos más ponderados y pertinentes sostienen que, ciertamente, los contenidos (la sustancia) importan: no solo constituyen el bagaje cultural que se ha ido construyendo y validando sino también el conjunto de palabras, significados y modelos teóricos que ayudan a comprender la educación y la formación docente, siendo esenciales para conferirles sentido, propósitos y sustentos conceptuales y prácticos.

No es el momento de componer una relación exhaustiva de los contenidos que merecen ser incluidos en el desarrollo profesional. En una síntesis reciente 
del tema se llevó a cabo una revisión de su devenir desde los ochenta hasta la fecha (Martínez y Rodríguez, 2017), con acuerdos, discusiones y propuestas interesantes. Nos limitaremos a proponer unas cuantas categorías temáticas, pero no con la intención de relatar todos los contenidos dignos de ser incluidos en cada una de ellas sino, más selectivamente, poner el acento a algunas consideraciones, persiguiendo también aquí la coherencia en la que se viene insistiendo. Dichas categorías se refieren a contenidos y conocimientos teórico-practico "para» la enseñanza, sabiduría práctica "del profesorado", conocimientos sobre organización, gobierno y gestión de centros, relaciones con familias y la comunidad, y conocimientos socioculturales y políticos sobre la educación y la formación.

\section{a) Conocimiento teórico-práctico}

El conocimiento teórico-practico "para» la enseñanza es una categoría plenamente reconocida (Shulman, 1986; EC, 2013). Incluye el amplio conjunto de valores, saberes, finalidades, objetivos y aprendizajes escolares, metodologías, materiales didácticos, reconocimiento y respuestas a las diversidades estudiantiles, relaciones pedagógicas, criterios y procedimientos de evaluación; así mismo, cabe señalar dentro de ella el currículo oficial establecido por los gobiernos y administraciones autonómicas, además de otras normativas que orientan y enmarcan el quehacer docente. Con las peculiaridades de unos y de otros, constituyen el conocimiento más formal y sistematizado, procedente de la investigación y del desarrollo de proyectos y experiencias, así como de tareas gubernamentales correspondientes a la ordenación de la educación. Se trata de un conocimiento externo al profesorado y propuesto -acaso requerido del mismo- «para» la enseñanza.

Lo expuesto en su momento a propósito de la educación de calidad en cuestión podría aducirse, sin más, sosteniendo que los contenidos y conocimientos que la justifican y la definen son los que tener en cuenta. Siendo algo más precisos, proceden algunas consideraciones acerca de dos subcategorías llamadas a componer el tipo de conocimientos que aquí se tratan: la primera se refiere a la formación científica, la segunda, a la formación pedagógica.

La formación científica del profesorado (en materias y áreas del currículo) es esencial al desarrollo profesional. De ella se ocupa la formación inicial y otros hitos profesionales, pero sea por los cambios experimentados en todos los campos del conocimiento o por la tarea perenne de aprender, viene siendo uno de los contenidos expresamente tratados en programas y actividades formativas corrientes. En línea con lo que se viene planteando caben algunas consideraciones pertinentes.

Giran en torno a la advertencia de que no basta con que la formación trate aspectos relativos a enseńanza de las diferentes áreas o materias curriculares. Es preciso, además, interrogarse y responder a cuestiones como qué lengua, matemáticas, ciencias, expresión artística, etc., vale la pena enseñar en las escuelas, así como qué aprendizajes múltiples e integrales del alumnado propiciar al trabajar con ellas. Qué epistemología procede tomar en consideración, atendiendo a la epistemología equitativa mencionada y a diferentes modalidades (interdisciplinares, problemas, proyec- 
tos, etc.) de organización del conocimiento pueden resultar intelectual, personal y socialmente más relevantes y significativas. O cómo desarrollar una conciencia crítica del profesorado respecto a la construcción histórica y sociocultural del conocimiento y su recontextualización curricular (Deng, 2007). Ello puede ser clave para tomar decisiones relativas a por qué y cómo los grandes temas y desafíos sociales, humanos, culturales, tecnológicos y ambientales que hoy interpelan a la educación escolarizada no pueden ser ajenos a la formación continuada.

Es imprescindible, por tanto, una formación científica de pleno derecho, aunque se han de problematizar los criterios habituales de la selección y organización de sus contenidos y conocimientos; en tales decisiones se juegan los márgenes de posibilidad de la educación del alumnado y la participación debida de todo alumnado en ella, sin que las visiones academicistas y exclusivamente racionales sobre la cultura escolar lo impidan arbitrariamente.

La segunda, formación pedagógica, también ocupa, de hecho, un lugar destacado (así se vio antes) en el desarrollo profesional corriente: bien lo merece, es fundamental para relacionar estrechamente el núcleo base constituido por contenidos formativos, estudiantes y aprendizajes, docentes y enseñanza (Darling Hammond y otros, 2017; Elmore, 2010). El abanico de los temas susceptibles de incluirse bajo esta subcategoría es considerable. Desde los relativos al conocimiento curricular idóneo y debidamente coordinado entre cursos y etapas educativas a los aprendizajes específicos y transversales que vale la pena promover; desde la diversidad de metodologías, recursos didácticos, el reconocimiento y valoración de las mochilas personales y sociales de cada estudiante a las relaciones sólidas, ricas, activas, creativas y estimulantes del aprendizaje escolar y, asimismo, los criterios, procedimientos y razón de ser de lo que se evalúe y cómo, convenientemente integrados en los propios procesos de enseñanza-aprendizaje y las diversas tareas docentes: planificación, interacciones pedagógicas, seguimiento y reflexión sobre la práctica.

Algunos caminos a seguir explorando, quizás con más claridad y propósitos que lo que suele ser habitual, conciernen a algunos enfoques pedagógicos dignos de atención. Está bien establecido que, de cara a una buena enseñanza, las bases psicológicas son ineludibles, pero no suficientes (Young, 2013). Una enseñanza coherente con una educación realmente inclusiva les presta una atención muy singular a los contextos sociales, familiares y digitales donde el alumnado de hoy en día vive, sueña, se socializa y moldea tanto sus propias identidades como los vínculos y relaciones que sostiene con los demás, con los iguales y con los docentes. Si se opta por una enseñanza-aprendizaje justa y equitativa, al trabajar la formación pedagógica del profesorado será preciso vertebrar mejor lo psicológico con lo social y cultural, lo que significa y comporta una educación culturalmente sólida con lo que ha de hacerse en las aulas para que resulte relevante y toque, constructivamente, las vidas, las mentes, los intereses del alumnado y las relaciones pedagógicas con ellos. En suma, una mirada más personal y social al mismo tiempo, centrada en los estudiantes como sujetos individuales y como sujetos con los demás, de forma que su paso por las escuelas, además de tomar en consideración sus intereses, motivaciones y vidas, no renuncia a ensancharlas intelectual, emocional, social y cívicamente: es decisivo que el desarrollo profesional lo tenga bien en cuenta o que lo eluda. 
Sin tales «sustancias» la formación didáctica puede quedar mermada y, más en concreto, no ser lo suficientemente sensible a reconocer y responder equitativamente a las desigualdades. El foco imprescindible en cuestiones acerca de cómo enseñar no ha de dejar fuera del foco, descuidar y hasta contribuir a que las brechas de las desigualdades educativas que nos aquejan persistan como lo vienen haciendo. Por ello mismo, en la formación pedagógica ha de abrir espacios mucho más explícitos a los aspectos emocionales y sociales del aprendizaje escolar, y también de la misma profesión, muy ligado con ello. Con la intención de llenar tales vacíos, se ha puesto de moda todo género de cursos y talleres sobre habilidades sociales, inteligencia emocional, resiliencia, resolución de conflictos, etc. Por importantes que sean, no resultarán provechosos si, planteados como tablas ilusorias de salvación al malestar escolar y profesional, se tratan desconectados de los demás elementos y relaciones del currículo, la enseńanza y la profesión docente. La calidad de la vida escolar, tan necesaria para docentes como para estudiantes, requiere insertarse con sentido y propósito en la calidad educativa justa y equitativa por alcanzar.

\section{b) Sabiduría práctica «del» profesorado}

Igual que la preposición "para» define los contenidos de la categoría precedente como algo externo que le es propuesto al profesorado, la preposición «de» sirve, ahora, para destacar que ahora nos referimos a conocimientos, teorías prácticas o implícitas que pertenecen a los docentes, a la sabiduría de la práctica generada y sostenida por ellos en sus tareas curriculares y pedagógicas (Marrero, 1991; Shulman, 1986). Se trata de conocimientos y contenidos estrechamente situados y ligados a la experiencia y la práctica. Su naturaleza es menos formal, codificada y sistemática que el precedente, siendo en buena medida hasta tácita. Lo que no significa que sea menos importante ni despreciable. No solo influye poderosamente en lo que piensan, viven y sienten, saben y hacen los docentes, sino que opera al mismo tiempo como un filtro (percepciones, sentimientos, juicios, apropiación o rechazo, etc.), mediador entre las teorías pedagógicas, el profesorado, la enseñanza-aprendizaje, las relaciones con los contenidos curriculares, los estudiantes y otros actores.

La sabiduría de la práctica, precisamente por donde surge, se crea, se mantiene o va cambiando por cada docente -su protagonista irremplazable-, viene a constituir una amalgama de elementos diversos y relaciones peculiares entre los mismos. Está hecha de creencias y concepciones, de juicios, valoraciones y propósitos, de vivencias y sentimientos (identidad y subjetividades docentes), de intenciones y sueños que orientan la acción, así como de determinados sistemas de atribución y explicación de aciertos y errores, de consistencias o contradicciones emanadas de la práctica y, también, de las relaciones sostenidas con otros, desde luego los estudiantes, pero también los colegas u otros actores. De manera que, si aquella reviste un carácter claramente personal ("cada maestrillo tiene su librillo»), no emana ni opera sobre el vacío. Al estar situada en los centros y resultar interactivamente recíproca con la sabiduría práctica, la cultura y los modos de hacer de otros prácticos, 
también es social, susceptible de surgir y mantenerse en comunidades de prácticas formales e informales, con unos efectos u otros.

A pesar de que este tipo de conocimiento reviste una importancia crucial para la profesión y las personas con quienes se ejerce, no suele incluirse, como un contenido sustantivo, en la formación continuada. Dada su naturaleza, pueden aducirse razones de peso para no abordarlo como algo de lo que se habla y teoriza, sino, más bien, como algo que vivir y practicar, concretamente a través de ciertos enfoques, metodologías y actividades a las que más adelante se tratan. La opción de reconocerlo puede tener alguna razón de ser. Por ejemplo, actuar de acuerdo con una cierta filosofía del desarrollo y aprendizaje docente según la cual son vistos con registros más amplios y expresivos. No como una formación instrumental y puesta al servicio exclusivo del conocimiento externo "para", sino como una que reconoce, valora, refuerza y reconstruye con el profesorado lo que sabe, hace, está viviendo y sintiendo en el ejercicio cotidiano de sus tareas y responsabilidades. De ese modo, el desarrollo profesional puede hacerse cargo de la cara más humana y situada, más cotidiana, vivencial y emocional de la docencia; explorar significados e implicaciones de la calidad educativa, la calidad de la vida escolar (también de los docentes), la citada ética profesional del cuidado. Pueden someterse a reflexión y cambio aquellas certezas conceptuales y prácticas que quizás convendría desaprender, o inseguridades sentidas que, dejadas de lado, cercenan las mejores ideas, proyectos y aspiraciones. A fin de cuentas, abordar sustantivamente estas temáticas, que tienen que ver con teorías implícitas docentes y asimismo con las relaciones sociales y emocionales sostenidas en positivo con el alumnado (con todos, pero particularmente con quienes más lo necesitan de las instituciones y profesionales), puede considerarse un verdadero reto al que responder con la coherencia a la que se viene haciendo mención.

\section{c) Conocimiento sobre organización, gobierno y gestión de centros, y relaciones con las familias y la comunidad}

Los contenidos de esta categoría son heterogéneos, pero intencionadamente se han incluido dentro de ella. Los primeros suelen ser objeto de formación, pero a veces sesgadamente; los segundos se omiten por lo general y no convendría seguir haciéndolo. En efecto, la prevalencia de un desarrollo profesional centrado sobre todo en la enseńanza y ajeno a la cultura, procesos y relaciones organizativas que conforman el ejercicio de la profesión (González, 2003) tiende a reducir los temas organizativos a estructuras y normativas oficiales, con un cariz marcadamente burocrático y administrativo. De ese modo, se deja de lado una visión ampliada y colegiada de la docencia, reforzando así una formación más individual que institucional. Se omite, entonces, el poder y los efectos de socialización que los centros ejercen sobre el profesorado que en ellos labora. Igualmente se pasan por alto las contribuciones que también a él le conciernen en orden a crear y sostener una organización escolar moral, inteligente, coordinada y sinérgica, educadora y habitable por las personas que la habitan (docentes, equipos directivos, otros profesionales, estudiantes). 
Si la educación de calidad en perspectiva requiere proyectos colectivos que vertebren con coherencia lo pedagógico, curricular, organizativo y profesional, dichos sesgos debieran subsanarse, no solo en la formación continuada, sino también, desde luego, en ella. Por ejemplo, los referidos al desarrollo del currículo por los centros y las correspondientes unidades organizativas, una cuestión esencial de la autonomía institucional bien entendida y responsablemente ejercida, no como algo a realizar por cumplir exigencias administrativas. Igualmente, temas acerca del liderazgo pedagógico, distribuido y democrático (Bolívar, 2012), de manera que no queden reservados en exclusiva al equipo directivo u otros cargos, sino abiertos y participados por todo el profesorado; puede ser una opción situada y consecuente de tratar y promover el sentido y la práctica de la tan cacareada colaboración docente o de las tan loables como distantes comunidades profesionales de aprendizaje. Convendría no tratarlos en exclusiva bajo el prisma de cómo llevarlos a cabo, sino mediante una formación que también proponga, analice y delibere con el profesorado sobre sus significados, sus porqués y paraqués más genuinos, sin ocultar las controversias que les afectan.

Asimismo, la inclusión de temáticas referidas a las relaciones con las familias y la comunidad dentro de esta misma categoría responde, de un lado, a que suele ser muy escasa, por no decir nula, su presencia en la formación al uso. Y, desde un punto de vista más sustantivo, a que representan uno de los flancos actualmente más controvertidos y dignos de ser tratados como merecen. Las deseables alianzas promoviendo participación y colaboración entre escuelas, docentes, familias y otros agentes municipales, comunitarios o de otros servicios ciudadanos, son clave en cualquier proyecto educativo que afronte con determinación la lucha contra la exclusión educativa y que apueste por la inclusión (Downes, Naiz-With y Susinate, 2017), siendo esta, por tanto, una lente con la cual mirar y redefinir los contenidos del desarrollo profesional. Tan pertinente es lo que se está planteando, que voces autorizadas en materia de formación inicial y continuada del profesorado lo reclaman (Zeichner, Bowman, Guillen, y Napolitan, 2016). Puede ser una excelente oportunidad de aprender de forma vivencial, no solo conceptual, una ocasión de aprender de y con distintas voces que participen, no solo con las de docentes o expertos; de que el mundo de lo cotidiano y social del alumnado entre con sus propios mensajes e implicaciones en el desarrollo profesional. En realidad, un territorio por recrear y constituir prestando oídos atentos a la profesionalidad comunitaria y democrática.

\section{d) Conocimientos sobre cambios sociopoliticos y reformas educativas}

Esta última categoría corresponde a los que venimos denominando aspectos de fuera, pero que, por lo dicho, no son ajenos a los de dentro: de ahí que merezcan la presencia correspondiente en el desarrollo profesional. Es patente que las reformas educativas y las demandas que representan para el profesorado suelen, ciertamente, ser objeto de la formación continuada. Con frecuencia, de una manera tan cambiante como obsesivamente empeñada en instrumentalizarla con afanes 
de regular, dirigir, ocupar y controlar el pensamiento y las prácticas docentes. No se quiere decir que el desarrollo profesional haya de ser ajeno a aquellas, pero no parece de más alguna advertencia pertinente al respecto. Precisamente en aras de la coherencia, una vez más, los contenidos de la formación debieran superar esa fiebre de las administraciones empeñadas en cambiarlos en razón de los temas estelares de moda que de cuando en cuando van surgiendo: lo episódico no debiera dejar de lado los retos perennes, pues una buena formación ha de ser, entre otras cosas, de plazos largos y sostenible. Y, asimismo, en línea con lo que se ha venido planteando, como quiera que las reformas, las de ahora y las de antańo, son buenos exponentes de factores, dinámicas, poderes e intereses macro, la formación docente no debiera acogerse al principio según el cual lo que hay que hacer es lo que está legislado. Debiera verse, más bien, como un espacio abierto, plural, sensible a las grandes cuestiones, preocupaciones y retos que están ahí más allá de las aulas, reclaman atención. Un espacio donde cultivar una profesionalidad consecuente con la ética de la crítica, con los imperativos de la justicia y la equidad, la dignidad y el respeto intelectual, social y personal que la profesión merece. Haciendo explícitos, debatiendo y deliberando los márgenes de posibilidad del trabajo docente y, al mismo tiempo, no pasando por alto las amenazas que se ciernen, hoy en día, sobre la profesión y su labor educativa.

A menos que pudiera sostenerse que el profesorado ha de ser un profesional técnico de miras cortas, hasta el punto de que los temas sociales, políticos e ideológicos que pugnan en el trasfondo del escenario ni le interesan ni afectan a sus vidas, no parece justificada la ausencia de tales contenidos, controversias y opciones sociales y educativas hoy en pugna. De forma que los temas con los que se abrió este texto, lejos de reducirse a lecturas e informaciones individuales -que seguramente muchos docentes realizan-, merecen ser colectivamente analizados y considerados, y ello puede contribuir a un desarrollo profesional con miras más amplias que las usuales.

\subsection{Procesos y actividades de Formación continuada}

El abanico de actividades, lugares, tiempos y relaciones en las cuales el profesorado puede ampliar, enriquecer, aprender y desaprender las «herramientas» diversas del oficio pueden ser ciertamente múltiples: desde las que, por ejemplo, ocurren cotidianamente con los estudiantes y las más individuales que permiten acceso a ideas, formas de trabajar, recursos didácticos y propician comprensión y uso práctico de las mismas hasta otras muy variadas, formales e informales, intencionales, previstas o emergentes realizadas con colegas, otros agentes (familias, inspectores, asesores y formadores, equipos directivos, etc.); se han descrito con profusión en la literatura especializada.

Tomando en consideración lo planteado previamente sobre la importancia de una formación explícita, formal, intencionada y planificada, nos vamos a referir a dos grupos de actividades: las que consisten en el acceso y comprensión del conocimiento base "para» la enseñanza y las que giran en torno a la sabiduría de la práctica, conocimiento «del» profesorado. 
a) Las primeras son, concretamente en nuestro contexto, las más formales, planificadas y participadas por el profesorado. Merecen valoraciones diferentes, negativas cuando son de estricto uso y consumo particular, obedecen a un modelo de formación externa, transmisivo y protagonizado por expertos, y responden a criterios e intereses que no vayan más allá de lograr certificación de méritos e incentivos estrictamente particulares. Cuando, por el contrario, se proponen, se comprometen y se llevan a cabo con propósitos de mejorar aprendizajes docentes, conectarlos con la renovación pedagógica y el avance en la calidad educativa expuesta, pueden ser mucho más positivas, y más aún, si están insertas, valoradas y comprometidas por alguna agenda de cambio y transformación educativa por los centros y otras unidades organizativas de los mismos. Precisamente en este último sentido, se trata de una modalidad de desarrollo profesional tan necesaria y relevante como otras diferentes, si las condiciones y relaciones creadas y participadas implican procesos activos, dialógicos y generadores de aprendizajes necesarios al buen ejercicio de la profesión.

Pueden contribuir a que el profesorado acceda y trabaje sobre nuevas ideas, metodologías, recursos y relaciones pedagógicas -formación científica y formación pedagógica integradas, e incluso sobre actividad que se citarán a continuación (amigos críticos)-, así como otros temas antes incluidos en la tercera y cuarta categoría de contenidos. Igualmente, pueden llevarse a cabo atendiendo a necesidades planteadas por centros y docentes, a proyectos e innovaciones que se proponen, resultando estas expresamente conectadas con la formación correspondiente. No hay, desde luego, fórmula alguna mágica para una buena formación de este tipo. Joyce y Showers (2003) han formulado una propuesta orientativa. Entienden que, además del valor y la relevancia de las temáticas a tratar, una secuencia de tareas y actividades puede ser formativamente provechosa. Consta de actividades consistentes en el tratamiento riguroso y estimulante de las bases teóricas, finalidades, metodologías e implicaciones prácticas del curso/taller, de otras que hacen posible la observación y simulación de casos y situaciones, la realización de prácticas por y entre los participantes y, finalmente, de la toma de decisiones concertadas acerca del uso situado, reflexivo y compartido en las aulas (u otros espacios educativos) por el profesorado en formación. Aunque no está de más recordar lo dicho a propósito de la teoría de la complejidad, cabe esperar que, planteadas y asumidas con coherencia tales actividades, pueden favorecer una comprensión profunda de contenidos y propuestas, relacionando teoría-práctica y propiciando diálogo pedagógico entre los participantes, el desarrollo y dominio de ciertas capacidades, conectando lo trabajado en los cursos o talleres con los lugares de trabajo, y tornar la formación externa en algo no yuxtapuesto y episódico, sino conectado con el día a día del profesorado y los propios centros.

b) Las segundas, que son las que quizás gozan de mejores avales y reconocimientos teóricos y prácticos, tienen una presencia mucho menor de lo que cabría esperar en el panorama general observado y descrito. El hecho de que sean actividades no solo cercanas sino inscritas en lo cotidiano, en problemas y aspiraciones emanadas de la práctica y sus agentes más directos; que sea el profesorado (individual y colegiadamente) su verdadero protagonista; giren en torno a profundizar la 
comprensión de la enseñanza-aprendizaje con propósitos de mejora y transformación; y sean exponentes, al menos potencialmente, de encuentros fructíferos entre teoría-sabiduría de la práctica-desempeño de la docencia son otras tantas razones que llevan a albergar en las mismas grandes expectativas (Hargreaves y Fullan, 2014).

Es considerable la lista de posibles actividades susceptibles de acogerse bajo este paraguas: proyectos y experiencia de investigación-acción, no solo entre docentes sino también con otros agentes escolares y sociales; realización de actividades de observación de clases entre iguales y el diseño de temas (lecciones), el desarrollo de los mismos en las aulas, el análisis, reflexión y aprendizajes consecuentes; la aplicación de un enfoque situado, práctico y clínico del desarrollo profesional; el diseño, desarrollo y evaluación de proyectos específicos o de mayor cobertura, áreas curriculares, ciclos, departamentos y centros como un todo; la apuesta por crear y sostener en cada uno de esos ámbitos y niveles comunidades profesionales de aprendizaje, tomadas como marco de referencia para la formación y renovación educativa, y desplegadas tanto presencial como virtualmente en redes profesionales, de centros, zonas, distritos escolares, por finalizar aquí una relación que podría ampliarse con otros ejemplos.

Dos apuntes pueden ser convenientes: uno, o el desarrollo profesional fluye y baña estos lares o, seguramente, no llegará a satisfacer con coherencia los valores y principios expuestos ni sus contribuciones llegarán a ser las esperables; dos, no porque las actividades giren sobre las diversas caras de aquella sabiduría práctica, que es esencial a los docentes y decisiva en muchos aspectos para ellos y otros agentes, serán por sí mismas valiosas y efectivas en la generación de los aprendizajes profundos e integrales (cognitivos, emocionales, sociales, éticos) de la profesión. Tan importante será mirar hacia dentro de las prácticas, sus actores y contextos, reconociéndolos como es menester, como ir más allá de una contemplación pasiva de cuáles son aquellas, sobre qué bases e intereses se sostienen y el grado en que merecen ser reconstruidas y transformadas.

\section{CONCLUSIONES}

Antes de finalizar, procede enunciar los apuntes que siguen a propósito de tres cuestiones una y otra vez mencionadas en el texto, los agentes, las responsabilidades y las condiciones locales y sistémicas propicias a la formación continuada necesaria.

En relación con los agentes, se ha insistido en que el protagonista por excelencia del desarrollo profesional es el profesorado (individual y colegiadamente), las personas que ejercen la docencia, cada una en lo más intransferible y en lo que comparte, es y aprende con los colegas, son quienes ocupan el centro del escenario, situados en un nivel micro y relacionado con otros meso y macro. Esa perspectiva, que en ningún modo puede aducirse por los docentes como una excusa respecto a lo que a ellos les concierne, permite sostener que también hay otros agentes interpelados, reclamándose de ellos sus respectivos roles complementarios. En definitiva, pueden considerarse tales todos los actores concernidos y afectados por la educación: estudiantes (uno de los más influyentes quizás en el profesorado), los equipos 
directivos de los centros, los servicios de las administraciones y sus profesionales, por ejemplo, inspectores $y$, por supuesto, los profesionales con perfiles de educadores de educadores, los poderes públicos, tanto en lo que atañe a políticas educativas como, desde luego, en lo que se refiere a su participación y decisiones en aquellas pugnas de las que se habló en el primer apartado. Dicho con otras palabras, los profesores con que cuenta un país no surgen de la nada, sino de las múltiples decisiones tomadas, contribuciones hechas u omisiones consentidas por muy diversos agentes además de los docentes.

Respecto a las responsabilidades, parece claro que, a pesar de que las miradas de alcance y las propuestas hechas en el artículo no son las únicas posibles (y seguramente no las mejores), podemos y debemos mirar hacia los aspectos por dentro de la educación, la profesión y el desarrollo profesional. Pero, o los que más poder tienen para tomar ciertas responsabilidades y decisiones efectivamente las comprometen, o los márgenes de posibilidad de esos tres asuntos seguirán más o menos como hasta la fecha o, acaso, irán a peor. Dicho con otras palabras, o se apuesta sin retóricas vacías, a escala global, Estado, y territorial, CC. AA., por una profesión docente mucho mejor reconocida y valorada en lo intelectual, respetada y bien cuidada en lo emocional, social y económicamente atractiva y remunerada, y, consecuentemente, se apuesta en firme por una sólida formación continuada (y la correspondiente a las otras etapas de profesionalización mencionadas) o, mal que nos pese, la educación de calidad justa y democrática, como un derecho esencial que asiste a todas las personas, seguirá dejada en los márgenes.

En lo que respecta a la creación de condiciones favorables, locales y sistémicas, no cabe sino volver a subrayar algo reiterado, reclamándolo aun con sentido de urgencia. En educación como en profesorado y desarrollo profesional, se ha logrado cubrir ciertas etapas del camino que son dignas de aprecio: no ha lugar a un halo de derrotismo que algunos sostienen con o sin justificación. Las que, sin embargo, quedan por andar son de tal calado que sería temerario refugiarse complacientemente en los oasis de excelencia que existen, en las buenas prácticas recientemente puestas de moda. $\mathrm{O}$ en cada CC. AA., zonas o distritos, centros y aulas, se crean condiciones favorables a la resolución coherente, justa y equitativa de los temas tratados o, quizás, cada vez más un mayor número de agentes concernidos e involucrados procurarán sacar del fuego las propias castañas dejando, insolidariamente, que las de los demás se quemen. Para que la educación en perspectiva, la profesión docente necesaria y la formación continuada coherente puedan habitar entre nosotros, habrán de crearse condiciones locales propicias y, simultáneamente, sistémicas. 


\section{REFERENCIAS BIBLIOGRÁFICAS}

Aguiló Bonet, A. (2009). «La universidad y la globalización alternativa: justicia cognitiva, diversidad epistemológica y democracia de saberes». Nómadas. Revista Crítica de Ciencias Sociales y Juridicas, 22 (2). https://www.redalyc.org/articulo.

Ainscow, M., Dyson, A. y Weiner, S. (2014). «From Exclusion to Inclusion. A review of international literature on ways of responding to students with special educational needs in schools». Clave Pedagógica, 13, 13-30.

Ariño, A. y Romero, J. (2016). La secesión de los ricos. Barcelona: Galaxia Gutenberg.

BALL, S. (2015). «Subjectivity as a site of struggle: refusing neoliberalism». British Journal of Sociology of Education, June, 1-18.

Barber, M. y Mourshed, M. (2008). Cómo hicieron los sistemas educativos con mejor desempeño del mundo para alcanzar sus objetivos. Recuperado de http://www.oei.es/pdfs/documento_ preal41.pdf.

Biesta, G. (2015). «What is Education For? On Good Education, Teacher Judgement, and Educational Professionalism». European Journal of Education, 50(1), 75-87.

Bourdieu, P. y Wacquant, L. (2005). Una invitación a la sociología reflexiva. México: Editorial Siglo XXI.

Borko, H., Jacobs, J. y Koellner, K. (2010). «Contemporary approaches to teacher professional development», in P. Peterson, E. Baker, \& B. McGaw (eds.), International encyclopedia of education (vol. 7, pp. 548-556). Oxford, England: Elsevier.

Cochram-Smith, M., Ell, F., Grudlow, L., Haighe, M. y Hill, M. (2014). «When Complexity Theory Meets Critical Realism: A Platform for Research on Initial Teacher Education». Teacher Education Quarterly, 41(1), 105-122.

Coffield, K. (2012). «Why the McKinsey reports will not improve school systems». Journal of Education Policy, 27(1), 131-149.

Darling-Hammond, L., Hyler, M.E. y Gardner, M. (2017). Effective Teacher Professional Development. Palo Alto, CA: Learning Policy Institute, http://creativecommons.org/licenses/ by-nc/4.0\%.

Deng, Z. (2007). «Transforming the Sub ject Matter: Examining the Intellectual Roots of Pedagogical Content Knowledge». Curriculum Inquiry, 37(3), 279-275.

Easton, L.B. (2008). «From Professional Development to Professional Learning». Phi Delta Kappan, 89(10), 755-761, https://doi.org/10.1177/0317270808901014.

Downes, P., Naiz-With, E. y Susinate, V (2017). Structural Indicators for Inclusive Systems in and around School. Analytical Report, Publication Office of the UE. Luxembourg, http:// epub.wu.ac.at $/ 5004$.

EC (2012). Supporting the Teaching Professions for Better Learning Outcomes. Commission Staff Working Document. Strasbourg, http://eur-lex.europa.eu.

EC (2013). Supporting teacher competence for better learning outcomes. Recuperado de http://ec.europa.eu/dgs/education_culture/teachercomp_en.pdf.

Eraut, M. (2012). «Developing a Broader Approach to Professional Learning», en McKee, A. y Eraut, M. (eds.), «Learning Trajectories, Innovation and Identity for 21 Professional Development». Innovation and Change in Professional Education 7, Springer Science. 
Escudero, J.M. (2016). «Éticas de la profesión docente y la lucha contra el fracaso escolar», en Escudero. J.M. (coord.), Inclusión y exclusión: Realidades, miradas y propuestas. Valencia. Nau Llibres.

Escudero, J.M. (2018). «Inclusión, justicia y equidad para la mejora de la educación», en Torrego, J.C. y Monge, C. (coords.), Inclusión educativa y aprendizaje cooperativo. Madrid: Síntesis.

Gale, E., Mills, C. y Cross, R. (2017) «Socially Inclusive Teaching: Belief, Design, Action and Pedagogic Work", Journal of Teacher Education, pp. 1-12.

Giroux, H. (2016). «Cultural Studies, Publica Pedagogy and the Responsabilities of Intellectuals». Communication and Cultural Studies, 1(1), 59-79.

GonzÁlez, M.T. (2003) (coord.). Organización y Gestión de Centros. Dimensiones y procesos. Madrid: Pearson.

González, MarT. y Cutanda, T. (2017). «Formación continuada del profesorado, mejora de la enseñanza y de los aprendizajes del alumnado». Revista Mexicana de Investigación Educativa, vol. 22(75), 1095-1116.

Guarro, A. (2002). Curriculum y Democracia. Barcelona: Octaedro.

Guarro, A., Martínez, B. y Portela, A. (2017). «Políticas de formación continuada del profesorado: análisis crítico del discurso oficial de Comunidades Autónomas». Profesorado, Revista de Currículum y Formación del Profesorado, 21(3), 21-40.

Hardy, I. (2012). The Politics of Teacher Professional Development. Policy, Research and Practice. New York: Routledge.

Hargreaves, A. y Fullan, M. (2014). Capital profesional. Madrid: Morata.

Kelly, P. (2006). «What is teacher learning? A sociocultural perspective». Oxford Review of Education, 34(4), 505-519.

Howard, P. (2018). «Twenty First Century Learning as Radical Re-Thinking of Education in the Service of Life». Education Sciences, 8(4), 1-13.

Joyce, B. y Showers, B.(2003). Student AChievement through Staff Development. NCSL. unrwa. org. site_coaching ss_cpd.pdf.

Laberee. D.F. (2011), «Targeting Teachers». Dissent, Summer, 9-14.

Marcelo, C. y Vaillant, D. (2009). Desarrollo profesional docente. ¿Cómo se aprende a enseñar? Madrid: Narcea.

Marcelo, C. (2011) (dir.). Estudio sobre la innovación educativa en España. Madrid: Ministerio Education. IFIE.educación.gob.es.

Martínez García, J. (2017). La equidad y la educación. Madrid: Catarata.

Martínez, B. y Rodríguez, M.J. (2017). «Los contenidos del desarrollo profesional docente: presencias y omisiones». Profesorado, Revista de Curriculum y Formación de Profesorado, 21(3), 41-61.

Marrero, J. (1991). «Teoría implícitas del profesorado y curriculum». Cuadernos de Pedagogía, n. ${ }^{\circ} 197$, pp. 66-69.

Ministerio de Educación y Formación Profesional (2019). Datos y cifras. Curso 2019-2020. Madrid: Secretaría General.

Monográfico Formación Continuada del Profesorado (2017). La formación continuada del profesorado de la educación obligatoria en el contexto español. Revista de Curriculum y Formación del Profesorado, https://recyt.fecyt.es/index.php/profesorado/issue/view/3100. 
Nieto, J.M. y Alfageme, M.B. (2017). «Enfoques, metodologías y actividades de formación docente». Profesorado, Revista de Currículum y Formación de Profesorado, 21(3), 63-81.

Novoa, A. (2019). «Tres tesis sobre el tercero. Repensando la formación docente». Revista Curriculum y Formación del Profesorado, 23(3). https://recyt.fecyt.es/index.php/profesorado/article/view/74494.

Sánchez Cuenca, I. (2019). La izquierda fin de (un) ciclo. Madrid: Catarata.

Shulman, L.S. (1986). «Those who understand: knowledge growth in teaching». Educational Researcher, 15(2), 4-14.

Stoll, L., Harris, A. y Handscomb, G. (2012). Great professional development which leads to great pedagogy: Nine claims from research. Notingham, UK: National College for School Leadership.

Timperley, H. (2010). Aprendizaje y desarrollo profesional docente. Ginebra, Suiza: OIE/UNESCO. http://www.ibe.unesco.org/sites/default/files/resources/edu-practices_18_spa.pdf-.

Trillo, F., Nieto, J.M., Martínez, B. y Escudero, J.M. (2017). «El Desarrollo Profesional y la Colaboración Docente: Un Análisis Situado en el Contexto Español de las Tensiones y Fracturas Entre la Teoría y la Práctica». Archivos Analiticos de Politicas Educativas, 27(117) http://dx.doi.org/10.14507/epaa.25.3316.

Zeichner, K., Bowman, M., Guillen, L. y Napolitan, K. (2016). «Engaging and Working in Solidarity With Local Communities in Preparing the Teachers of Their Children». Journal of Teacher Education, August, 1-14.

Young, M. (2013). "Overcoming the crisis in curriculum theory: a knowledge-based approach». Curriculum Studies, 45(2), 101-118. 
